\title{
Cognitive approach to auditory observed from the position of the Observer - interpreter
}

\author{
Olga Eryomina $^{1, *}$ \\ ${ }^{1}$ Department of foreign languages № 2, Institute of linguistics and Intercultural communication, Irkutsk National Research Technical \\ University, 83, Lermontov street, 664074 Irkutsk, Russian Federation
}

\begin{abstract}
An Observer can act as an instrument of conceptual and semantic analyses. The analysis is not reduced to sensor perception only. Such aspects of perception as mental, evaluative and affective or emotional are not less relevant. In this case an Observer acts an evaluating and perceiving party. The Observer's functioning is strongly affected by the nature of the observed. The permanent fact is that when we are discussing an Observer there is always something observed. An Observer perceives the subject matter and evaluates the situation as a whole. The observed phenomenon and events are interpreted by the Observer through speech-act verbs such as to hiss, to bleat, to grumble, to babble. The semantic meaning of these predicates contains a perceptive and evaluative component, which in its turn means an Observer present. The last one perceives, interprets and evaluates not just the proposition of the speech act, but the so called paralinguistic component, not less relevant in the communicative process. The article considers an issue on different cognitive and affective states of an Observer - interpreter of a communicative speech act, caused by a specific speech manner of communicants.
\end{abstract}

\section{Introduction}

\subsection{The notion of the terms 'observation' and 'observed'}

If we study the 'observation' as the ground zero, it can be defined as the universal cognitive composition, containing scientific notions [1]. G.V. Osipov defines observation as the way of learning the world in an extended sense. The author marks out two types of observation: trivial and scientific. Trivial observation is a human activity providing information about the outer world. Scientific observation is aimed at the achieving definite scientific purpose [2]. Participant observation is of main interest for us. It involves acquiring knowledge about a human being as a definite cultural type.

Large encyclopedic dictionary defines observation as "aimed perception determined by activity's task" [3]. Observation is the process of perceptive and cognitive interaction between an Observer (perceptive and cognitive subject) and the observed. The observed in its turn is something perceived phonetically or visually. The observation model provides two necessary components: an Observer and observed.

\subsubsection{Notions of Observer and observed}

We define an Observer as the subject of perception, interpretation and evaluation in the communication process. Biological and cognitive theories of cognition determine an Observer as a living biological and psychological system in its interaction with the reality (both inside and outside, physical and psychological) $[4,5]$. J. Searle defines an Observer as an intentional maker, user and designer of reality [6, 7]. U. Maturana in his turn analyses an Observer as a part of a languaging process. He considers that an Observer (as other speech act participants) arises and exists in a languaging.

According to U.D. Apresyan an Observer combines perception and evaluation conceptualizing facts and events of reality [8]. The most relevant point in the linguistic conceptualization of an Observer is the fact that an Observer combines perceptive and evaluative processes, he/she synthesizes perception and evaluation in the communicative process, using peculiar speech verbs, such as to hiss, to snarl, to chirp to describe a communicative act. An Observer as a cognitive subject perceives events of the outer world and evaluates the situation as a whole.

It is evident that an Observed is caused by an Observer. The category of an observed is of universal character. It may comprise both universal experience (linguistic world image) and any of its parts (eventive, mental, emotional, spiritual) [9].

\footnotetext{
* Corresponding author: miamina@mail.ru
} 


\section{Materials and methods}

\subsection{Situation of observation: cognitive model}

The main task of a cognitive model is to explain such language factors as the Observer's application towards different modes of perception and types of an observed.

From our perspective the situation of observation must represent the description of all potential observation types not only inner (moral) but also visual observed (examined).

Visual observed is a physiological act/mechanism describing the process of observation concerning a human being. This process can cause cognitive changes in the Observer himself. Inner (moral observed) - this is a non-observed process of an individual's knowledge formation. It is defined by the Observer's cultural and language identity [10].

Visual observed patterns and events are perceived by the subject visually. Auditory observed result of cognitive interaction is between the Observer and the outside world.

The auditory/phonetically observed is a part of perceptive and evaluative complex in the semantics of a set of English speech act verbs. An Observer as a cognitive and perceptive subject appears during the process of observation. This whole process along with the peculiarities of a speech act subject is interpreted by an Observer, who may act as an addressee or an outside listener of a speech act, not less relevant. Upon that an observed includes all possible voice characteristics of communicants' speech. "Welcome, Professor Shreetin," the receptionist chirped through his Buffalo Bill Van Dyke as sincerely as someone who'd just added bleach to your coffee [11]; Two days later, Angela called, and an hour later, I was in her car. "I am so excited!" she chirped like a sparrow on caffeine [12]. Examples illustrate cheerful speech of communicants interpreted by an Observer with the help of speech verb to chirp, which is defined in the English language dictionary as follows: to speak in a happy high voice [13]. Voice characteristics of communicants motivated an Observer who perceived, interpreted and evaluated expressive speech behavior of communicants to describe speech pronounced in a happy high voice with the illocutionary verb to chirp in order to represent the whole communicative act as cheerful.

\section{Results}

\subsection{The perceptive nature of the semantics of some speech act verbs in the English language}

Perceptive and evaluative complex combines two aspects of perception and evaluation of a communicative act. They are voice characteristics of a speech subject and description, evaluation of different cognitive and affective states of an Observer and speech act subjects. Sound voice characteristic is the key point in analyzing speech verbs with perceptive and evaluative semantic meaning, such as (to snarl, to hiss, to babble).

Both paralinguistic and verbal components of communication can be determined in the speech act. After the manner of S.V. Kodzasov [14] we distinguish parametric and melodic voice characteristics of a speech subject, such as: low/loud voice, high/high-pitched voice, snappish, abrupt, curt, in a repetitious manner etc. These characteristics show different cognitive and affective states of both: speech subject and an Observer, who interprets the communicative act, and moreover can act as an addressee. As there arises an issue, whether characteristics of speech act made by an Observer are subjective, it is necessary to point out that all the statements are made on the basis of data from English language dictionaries and Corpus linguistics.

Tonality/tone rage is one of the most important components of the evaluativity. It has interpretative character and is the mode through which an author conceptualizes proposition. The tonality characterizes how the proposition was said. It appears as the result of necessity to express evaluation in the process of communication. Tonality has been defined through the choice by the speaker of definite expressive lexical units (illocutionary verbs/speech verbs).

The interpretative component exists in the semantics of such predicates as to snap, to chirp, to hiss, to rattle. This characteristic proves existence of / and a descriptive component, when conceptualizing a speech act. An Observer can act both a speech act subject and an addressee. "Ben comes for a visit and they pounce on him thinking because he works in our family's restaurant back in Italy he can help, he can make all this better» He rattled on, each word overlapping the next [15]; «The prisoner has been found guilty of treason against the Authority by crimes committed in the name of Aaron», Enderson said. His voice rattled the fragile wooden walls in the narrow hallway and made Remko's mind spin [16]. Communicative predicate to rattle is defined in the dictionaries as follows: to say, perform, or affect in a brisk lively fashion [17]; to chatter idly; talk, esp. at length [18]. The distinctive characteristics brisk, lively, idly are deviations from the pronouncing norm, which attracted Observer's attention with their odd, untypical and non-normative speech.

Attention is the basic component during the perceptive process. Voice characteristics of a speech act subject are 'natural marks' which can be identified with the sounds of different etymology. The effective and evaluative reaction of the Observer is caused by objective parametric deviations from the pronouncing norm. The examples presented above describe the speech of a subject of the communicative act as lively, jerky, rumbling.

Communicative predicate to hiss has the following definitions: to utter or whisper angrily 
or threateningly and with a hiss [19]; if you hiss something, you say it forcefully in a whisper [20]; to say something in a loud whisper [21]. Presented components: angrily, threateningly, in a loud whisper show negative speech act subject relation towards an addressee. "How dare you say my name out here?" he hissed [22]; You should listen to me when I'm saying something to you," she hissed and grabbed my shoulder from behind, turning me roughly around to face her [23]. Both examples illustrate negative relation towards an addressee. An Observer perceives, interprets and evaluates expressive speech behavior of communicants and communicative act as a whole. Observer's affective and evaluative reaction (negative in this particular case) is motivated by the parametric deviations from the pronouncing norm.

\section{Discussion}

\subsection{Balance of notions 'emotional breadth' and evaluativity}

A human being is always accompanied by paralinguistic and pragmatic means of communication in the communicative process. T.A. Van Deik stated that every communicative act has pragmatic context: physical or biological [24]. In the communication process spontaneous particular movements, gestures, poses and emotions are common to persons. "Jesus, Bax," the salt-andpepper-haired companion grumbled, a hint of admiration mixing with his shock as he scrambled to collect the papers getting crinkled [25].

A speech act subject can have different feelings during the communicative process, such as disgust, shock or admiration. The most important point is that an Observer makes an attempt not just to describe the communicative situation mechanically. An Observer attempts to create an image of a speech act subject. So it logically follows that not the proposition steps forward, but the way how it was said, pronounced does [26].

Emotions and evaluation exist in cause-effect relationship [27]. It was V.I. Shakhovsky who introduced the term emotional breadth in Russian linguistics to identify expression of emotions in the communicative process [28]. "That's a fine way $t$ ' wake up a husband after a year's absence," he grumbled happily, throwing an arm about her shoulder [29]. The adverb happily describes speaker's speech manner as cheerful and fascinated. The author marks that there is a strong relationship between emotional breadth and evaluativity. Modern linguistics uses these terms as synonyms [30]. Emotional breadth may be of both: usual and contextual character.

An Observer perceives, evaluates and interprets cognitive and affective states of communicants through pragmatic meaning of a set of communicative predicates (to bleat, to snarl, to babble) with perceptive and evaluative semantics. "It's a fake," he bleated pitifully [31]; A strong tenor voice bleated, "Hail in all humbleness the royal sun where he awaits below the dawn's horizon! May entry be vouchsafed the servants of his magnificence who loyally attend his plea-sure?" [32]. Communicant's speech in the example [31] can be described as mournful, plaintive and bleating. However example [32] illustrates opposite effect on the Observer - interpreter what comes from the characteristic component a strong tenor voice, describing intentional speech manner of the communicative act subject. "It acted so friendly and then when I tried to pet it, it bit me and I was so shocked I just reacted, I wasn't thinking, I'm sorry. But it doesn't look like it got hurt much, at least I hope it didn't -- "I babbled on, the customers watching, until she told me in a tight voice that it was okay, it hadn't been my fault, she'd seen the whole thing, she didn't know what had gotten into the cat, and of course they'd pay for any medical bills [33]. Example [33] illustrates desultory conversation, idle talk, blabber which was finally interrupted by the other speech act subject until she told me in a tight voice.... He / she can act both an addressee and an outside Observer - listener forming a pattern of speakers' communicative behavior. Communicative predicates introducing not only direct but also indirect speech are forming this image.

The world of emotions has been expressed through lexical units of different types (illocutionary speech verbs). In any emotional state a human being conveys emotions through his/her speech behavior. However it is necessary to mention that there is a difference between intentional expression of emotions and spontaneous one. Emotions have been expressed in the communication process through intonation. It has served as the basic mean to express emotions in a speech act. Emotional breadth can be of usual character. An Observer does not just describe a communicative act, he/she perceives and evaluates cognitive and affective states of communicants through peculiar speech verbs (to chirp, to snarl) with perceptive and evaluative semantics.

\section{Conclusion}

J. Searle studying observation drew a conclusion that an Observer is an intentional maker/producer, user and designer of the outside world. Otherwise stated an Observer is a fundamental, epistemological culturally based instrument. An Observer lives and exists in a languaging, in discourse. He/she can be used as an analytical instrument in conceptual and semantic analysis, especially when it is necessary to determine and describe different cognitive and affective states of a speech act subject. An Observer can combine roles of perceptive subject and evaluative one. When the question is about an Observer, we always refer to the observed. An 
Observer interprets events of the real world through language, namely by means of communicative predicates such as to hiss, to bleat, to grumble, to babble. These predicates exist in a language as evidence of an Observer who interprets voice complex of communicants. An Observer points out sound peculiarities (quick, high-pitched, loud. low etc.) of speech. Speech meaning of illocutionary verbs contains perceptive and evaluative sense. What in its turn implicates an Observer present?

An Observer's task is not just to communicate the proposition, but to interpret and evaluate it as a whole. It is unconditional that the proposition is apparently important in its informative meaning, but the paralinguistic side of communicative act is also relevant. It illustrates that cognition is undeniable part of human activity and a communication process is the part of it $[34,35]$.

\section{References}

1. T.L. Verkhoturova, Philosophical linguistics nature of the metacategory of an Observer (ISLU, Irkutsk, 2009)

2. G.V. Osipov Russian sociological encyclopedia (NORMA-INFRA group, Moscow, 1998)

3. Large encyclopedic dictionary. Retrieved from: http://www.dic.academic.ru (2019)

4. H.R. Maturana, The nature of the laws of nature, Systems Research and Behavioral Science 17, 459-568, (2000)

5. H.R. Maturana, Autopoiesis, structural coupling and cognition: a history of these and other notions in the biology of cognition, Cybernetics and Human Knowing 9 (3/4), 5-34, (2002)

6. J. Searle, Mind, Language and Society. Philosophy in the Real World (Basic Books, N.Y., 1999)

7. A. Kravchenko, Cognitive linguistics, biology of cognition and biosemiotics: Bridging the gaps, Language Sciences 28 (1), 51-75. Retrieved from: https://doi.org/10.1016/j.langsci.2005.02.002 (2006)

8. U.D. Apresyan, Native theoretical semantics in the end of the $X X$ century, Izvestia RAN 4 (58), (1999)

9. T.L. Verkhoturova, The factor of an Observer in the scientific language (ISLU, Irkutsk, 2008)

10. N.Riemer, Cognitive linguistics and the public mind: Idealist doctrines, materialist histories, Language and communication 64, 38-52. Retrieved from: https://doi.org/10.1016/j.langcom.2018.09.002 (2019)

11. Corpus of Contemporary American English (COCA), COCA 262016 FIC Analog. Retrieved from: https://www.english-corpora.org/coca/ (2019)
12. Corpus of Contemporary American English (COCA), COCA $105 \quad 2012$ FIC Bk:DeaderHomesGardens. Retrieved from: https://www.english-corpora.org/coca/ (2019)

13. English language dictionary. Retrieved from: http://www.ldoceonline.com/dictionary/ (2019)

14. S.V. Kodzasov Voice: characteristics, functions and nominations, Language about language, 502526, (2000) (in Russian)

15. Corpus of Contemporary American English (COCA), COCA 102017 FIC. Retrieved from: https://corpus.byu.edu/ (2019)

16. Corpus of Contemporary American English (COCA), 202017 FIC. Retrieved from: https://corpus.byu.edu/coca/ (2019)

17. English language dictionary. Retrieved from: http://www.merriam-webster.com/dictionary/ (2019)

18. English language dictionary. Retrieved from: http://www.collinsdictionary.com/dictionary/engli $\underline{\mathrm{sh} /}$ (2019)

19. English language dictionary. Retrieved from: http://www.merriam-webster.com/dictionary/ (2019)

20. English language dictionary. Retrieved from: http://www.collinsdictionary.com/dictionary/engli $\underline{\mathrm{sh} /}$ (2019)

21. English language dictionary. Retrieved from: http://www.ldoceonline.com/dictionary/ (2019)

22. Corpus of Contemporary American English (COCA), COCA $12 \quad 2017 \quad$ FIC Bk:CompanyTown. Retrieved from: https://corpus.byu.edu/ (2019)

23. Corpus of Contemporary American English (COCA), COCA 772016 FIC Bk:BoringGirls. Retrieved from: https://corpus.byu.edu/ (2019)

24. T.A. van Deik, Language. Cognition. Communication (Progress, Moscow, 1989) (in Russian)

25. Corpus of Contemporary American English (COCA),76 2016 FIC: Bk:BurnedDeep. Retrieved from: https://corpus.byu.edu/coca/ (2019)

26. O.V. Eryomina, Cognitive analysis experience of paralinguistic aspect in communication (on the material of English speech verbs) (ISU, Irkutsk, 2013)

27. Malinovich, U.M., Valuables hierarchy of a human being inside and outside world, Linguistics and axiology: ethnic semiometry of value-based sense, 77-98, (2011)

28. V.I. Shakhovsky, Categorization of emotions in lexical and semantic language system (University of Voronezh, Voronezh, 1987)

29. Corpus of Contemporary American English (COCA), 1162016 FIC. Retrieved from: https://corpus.byu.edu/coca/ (2019) 
30. E.M. Volf, Functional semantics of an evaluation (Editorial YRSS, Moscow, 2002)

31. Corpus of Contemporary American English (COCA), 402010 FIC Analog. Retrieved from: https://corpus.byu.edu/coca/ (2019)

32. Corpus of Contemporary American English (COCA), 1061993 FIC BkSF:SplitHeirs. Retrieved from: https://corpus.byu.edu/coca/ (2019)

33. Corpus of Contemporary American English (COCA), 242014 FIC FantasySciFi. Retrieved from: https://corpus.byu.edu/coca/ (2019)
34. W.Van Praet, G. O'Grady, The prosody of specification: Discourse intonational cues to setting up a variable, Journal of pragmatics 135, 87-100. Retrieved from:: https://doi.org/10.1016/j.pragma.2018.07.013 (2018)

35. J. Romero-Trillo, Prosodic pragmatics and feedback in intercultural communication, Journal of Pragmatics. Retrieved from: https://doi.org/10.1016/j.pragma.2019.02.018 (2019) 